\title{
Directed Causal Network Construction Using Linkage Analysis with Metabolic Syndrome-Related Expression Quantitative Traits
}

\author{
Kyee-Zu Kim ${ }^{1}$, Jin-Young Min², Geun Yong Kwon ${ }^{3}$, \\ Joohon Sung ${ }^{1,2}$ and Sung-II $\mathrm{Cho}^{1,2 *}$
}

${ }^{1}$ Graduate School of Public Health, Seoul National University, ${ }^{2}$ Institute of Health \& Environment, Seoul National University, Seoul 151-742, ${ }^{3}$ Division of Epidemic Intelligence Service, Korea Centers for Disease Control and Prevention, Osong 363-951, Korea

\begin{abstract}
In this study, we propose a novel, intuitive method of constructing an expression quantitative trait (eQT) network that is related to the metabolic syndrome using LOD scores and peak loci for selected eQTs, based on the concept of gene-gene interactions. We selected 49 eQTs that were related to insulin resistance. A variance component linkage analysis was performed to explore the expression loci of each of the eQTs. The linkage peak loci were investigated, and the "support zone" was defined within boundaries of an LOD score of 0.5 from the peak. If one gene was located within the "support zone" of the peak loci for the eQT of another gene, the relationship was considered as a potential "directed causal pathway" from the former to the latter gene. SNP markers under the linkage peaks or within the support zone were searched for in the database to identify the genes at the loci. Two groups of gene networks were formed separately around the genes IRS2 and UGCGL2. The findings indicated evidence of networks between genes that were related to the metabolic syndrome. The use of linkage analysis enabled the construction of directed causal networks. This methodology showed that characterizing and locating eQTs can provide an effective means of constructing a genetic network.
\end{abstract}

Keywords: genetic network, expression quantitative trait, linkage analysis, metabolic syndrome

\section{Introduction}

The genetics of complex diseases is a continuous chal-

*Corresponding author: E-mail persontime@hotmail.com Tel +82-2-880-2717, Fax +82-2-743-8240

Received 15 November 2011, Revised 26 November 2011, Accepted 30 November 2011 lenge in human genetic studies and chronic disease epidemiology due to the complexity of its biological implications. Metabolic syndrome, which is diverse in pathology and considered to be a growing health problem, consists of a cluster of endocrine-metabolic disorders, such as hypertension, dyslipidemia, glucose intolerance, and abdominal obesity (Reaven, 2002). Insulin resistance has been considered an underlying risk factor of these endocrine disorders (Reaven, 1988), and its pathological or epidemiological characteristics have been continually investigated, including its genetic aspects. Genetic studies on metabolic syndrome have been conducted mostly using the candidate gene approach, with much success in identifying its genetic components (Bonnet et al., 2008; Groop, 2000; Horenstein and Shuldiner, 2004; Ma et al., 2007; Mercado et al., 2002; Sale et al., 2006; Stern, 2003; Vasseur et al., 2006; Wang et al., 2004; Yang and Chuang, 2006). Some studies have focused on the relationships between components of the metabolic syndrome (Kopf et al., 2008; Mussig et al., 2009) or among the candidate genes that are related to it (Foufelle and Ferre, 2002). However, the mechanism that underlies the interrelationships between related genes has been not fully determined, and although various genes contribute to the disease, the effect size of a single gene is very weak.

Understanding genetic components represents a challenge in not only insulin resistance but also most complex diseases. To unravel the underlying genetic mechanisms for complex diseases, various concepts and methods have been applied, such as gene-network (Wessels et al., 2001), pathway analysis (Yu et al., 2009), and gene-regulator approaches (de Jong, 2002; Hasty et al., 2001). Gene set approaches, such as network modeling, can be utilized when information on the genetic pathway is lacking.

Various studies have contributed to determining genegene interactions by constructing gene network models using several statistical approaches (Markou and Singh, 2003a). Some studies have applied computational methods, such as neural network models (Markou and Singh, 2003b; Vohradsky, 2001). Gene network models that are based on statistical and computational approaches have been helpful in detecting the "lines" of gene-gene interactions. However, exploring the biological or functional directions of network lines still remains a challenge, be- 
cause the biological implication of these models has mostly been unconsidered and because interpreting the metabolic pathway among the networked genes can be difficult. The biological aspect of disease-related metabolites must be taken into account due to its importance in understanding gene-gene interactions. A clear example can be seen in the components of metabolic syndrome, such as insulin, lipid, glucose, and adiponectin, which interact with each other. Glucose metabolism interacts with lipid metabolism via the central nervous system (Schulingkamp et al., 2000). The insulin pathway is associated with adipose metabolism, which is evident in certain disorders, such as fatty liver disease (Bouzakri et al., 2006; Kantartzis et al., 2009; Previs et al., 2000). The challenges, nonetheless, are in detecting the interactions and effects of genes on each other.

To solve this problem, some studies have suggested the concept of a causal network, which consists of biological functions and implications in the gene network construction (Schadt and Lum, 2006). This approach has been useful in clarifying how genetic networks intervene in the biological pathway of animal populations (Kulp and Jagalur, 2006; Schadt et al., 2005; Tu et al., 2006). In humans, however, the causal genetic network remains a challenge because of its complexity and numerous associated factors, including environmental and behavioral variables.

In this study, we demonstrated a simple, intuitive method of constructing a directed causal network with an expression quantitative trait (eQT) that is related to metabolic syndrome. We aimed to explore the direction that supported the biological function of the eQTs and not base our interpretation solely on statistical significance. To identify the direction, we used information from the peak loci of each eQT via variance component linkage analysis. The use of these eQTs, which was obtained during mRNA transcription, can be helpful in identifying the genetic components that are associated with disease (Rockman and Kruglyak, 2006). In the Materials and Methods section, we describe the data that we obtained and the eQT selection criteria. The methodology of constructing the directed gene network modelvia linkage analysis is also referred to in this section. In the Results section, we present the linkage peak loci and logarithm of the odds (base 10) (LOD) scores of important eQTs. We also describe the gene network model that is associated with metabolic syndrome by matching the peak loci and several specific genes. In the Discussion section, we show the biological implication of our results with an inquiry into our methodology of gene network construction.

\section{Methods}

\section{Data and materials}

Data were obtained from Problem 1 (Genetics of Gene Expression Variation in Humans) of the 15th Genetic Analysis Workshop (GAW15) and contained 194 individuals in 14 3-generation Centre d'Etude du Polymorphisme Humain (CEPH) Utah families (Cheung and Spielman, 2007; Morley et al., 2004). The expression levels of 3554 genes in lymphoblastic cells were analyzed as phenotypes. From these genes, we selected 49 eQTs that are known to be associated with insulin resistance, based on previous studies and gene databases. The basic characteristics of the selected eQTs are presented in Table 1.

The genotype data were collected for 2884 singlenucleotide polymorphism (SNP) markers across 22 autosomal chromosomes and the X-linked chromosome from 194 individuals. Sex-averaged Rutgers Combined LinkagePhysical Map (Matise et al., 2007) was matched with the original map file to account for the recombination fraction of given SNP markers.

\section{Gene network model construction via linkage analysis}

For each of the 49 metabolic syndrome-related eQTs, variance component linkage analysis, which is commonly used for mapping quantitative trait loci, was performed to search the genomic loci with a linkage peak across 22 autosomal chromosomes. Note that the X-linked 23rd chromosome was excluded from the investigation. The linkage peak loci were investigated, and the "support zone" was defined within the bounds up to an LOD score of 0.5 from the peak. Fig. 1 represents an example of a linkage peak point and support zone identification with an eQT of the IRS2 gene.

To explore gene-gene interactions, we studied the relationships between all possible pairs of the 49 genes. We investigated whether SNP markers, which are located on the linkage peak, were found in several specific genes. If one gene was located within the "support zone" of the peak loci for the eQT of another gene, the relationship was considered as a potential "directed causal pathway" from the former to the latter gene, according to the following logic; if there is a linkage between $\mathrm{eQT}$ as a phenotype and a genetic locus, the causal direction can be assumed to be from the gene to the phenotype, rather than the opposite direction. Since a particular eQT represents the function of the underlying gene (e.g., A), the greatest linkage signal is observed on the locus of $A$. In addition, if the eQT for $A$ 
Table 1. Locations and gene IDs of 49 insulin resistance-related eQTs located on 22 autosomal chromosomes

\begin{tabular}{|c|c|c|c|c|c|}
\hline Gene ID & eQT & Location & Gene ID & eQT & Location \\
\hline 203411_s_at & LMNA & $1 q 21.2-q 21.3$ & 209122_at & ADFP & $9 p 22.1$ \\
\hline 202377_at & LEPR & $1 p 31.2$ & 209822_s_at & VLDLR & $9 p 24$ \\
\hline 209094_at & DDAH1 & $1 \mathrm{p} 22$ & 203327_at & IDE & $10 q 23-q 25$ \\
\hline 200788_s_at & PEA15 & $1 \mathrm{q} 21.1$ & 209468_at & LRP5 & $11 q 13.4$ \\
\hline 205282_at & LRP8 & $1 \mathrm{p} 34$ & 203683_s_at & VEGFB & $11 q 13$ \\
\hline 206060_s_at & PTPN22 & 1p13.3-p13.1 & 209541_at & IGF1 & $12 q 22-q 23$ \\
\hline 204852_s_at & PTPN7 & $1 q 32.1$ & 200921_s_at & BTG1 & $12 q 22$ \\
\hline 205720_at & POMC & $2 p 23.3$ & 206687_s_at & PTPN6 & $12 \mathrm{p} 13$ \\
\hline 202718_at & IGFBP2 & $2 q 33-q 34$ & 209185_s_at & IRS2 & $13 q 34$ \\
\hline 218257_s_at & UGCGL1 & $2 q 14.3$ & 218801_at & UGCGL2 & $13 q 32.1$ \\
\hline 205480_s_at & UGP2 & $2 p 14-p 13$ & 212858_at & PAQR4 & $16 \mathrm{p} 13.3$ \\
\hline 200643_at & HDLBP & $2 q 3$ & 201508_at & IGFBP4 & $17 q 12-q 21.1$ \\
\hline 219497_s_at & BCL11A & $2 \mathrm{p} 16.1$ & 203685_at & BCL2 & $18 q 21.33$ \\
\hline 203555_at & PTPN18 & $2 q 21.1$ & 213136_at & PTPN2 & $18 p 11.3-p 11.2$ \\
\hline 213521_at & PTPN18 & $2 q 21.1$ & 213792_s_at & INSR & $19 p 13.3-p 13.2$ \\
\hline 208510_s_at & PPARG & $3 p 25$ & 202068_s_at & LDLR & $19 \mathrm{p} 13.3$ \\
\hline 203343_at & UGDH & $4 p 15.1$ & 204908_s_at & BCL3 & $19 q 13.1-q 13.2$ \\
\hline 204201_s_at & PTPN13 & $4 q 21.3$ & 202716_at & PTPN1 & $20 q 13.1-q 13.2$ \\
\hline 207113_s_at & TNF & $6 p 21.3$ & 206632_s_at & АРОВЕСЗВ & $22 q 13.1-q 13.2$ \\
\hline 201393_s_at & IGF2R & $6 q 26$ & 204205_at & АРОВЕСЗG & $22 q 13.1-q 13.2$ \\
\hline 210512_s_at & VEGF & $6 \mathrm{p} 12$ & 209546_s_at & APOL1 & $22 q 13.1$ \\
\hline 205581_s_at & NOS3 & $7 q 36$ & 221013_s_at & APOL2 & $22 q 12$ \\
\hline 205207_at & IL6 & $7 \mathrm{p} 21$ & 221087_s_at & APOL3 & $22 q 13.1$ \\
\hline 205084_at & BCAP29 & $7 q 22-q 31$ & 219716_at & APOL6 & $22 q 12.3$ \\
\hline 202006_at & PTPN12 & $7 q 11.23$ & & & \\
\hline
\end{tabular}

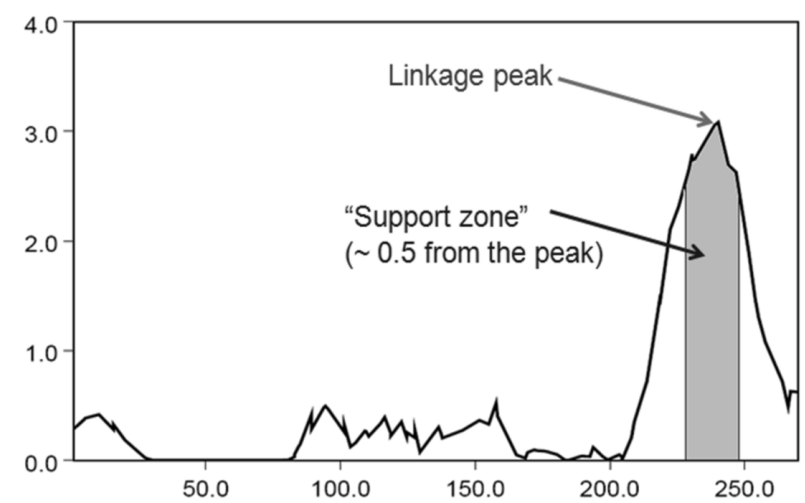

Fig. 1. Example of identification of the linkage peak point and support zone.

is also linked with another gene $B$, this linkage also implies a causal direction from gene B to the eQT phenotype, which suggests a causal connection from gene $B$ to gene A, which underlies the eQT. Genes from the 49 selected eQTs were preferentially included in the metabolic syndrome-related gene network model due to their association with the mechanisms of the disease. Other genes, which were identified with SNP markers in the support zone, were also added in the directed network model. Merlin 1.1.2 software was used for the variance component linkage analysis.

\section{Results}

\section{Linkage analysis of eQTs}

To identify the network model of the gene expression levels that were related to metabolic syndrome, variance component linkage analyses were performed individually with the 49 selected eQTs. Table 2 represents the LOD scores and linkage peak loci of 14 eQTs. We identified about 14 linkage peaks with LOD scores $>2.0$ for eQTs, with 6 of these eQTs displaying LOD scores $>2.5$. For the genes ADFP and IRS2, the highest LOD scores of 3.09 and 3.08 were observed at SNPs on chromosomes 5 and 2 , respectively.

\section{Comparison of linkage peak loci}

To explore gene-gene interactions, we investigated whether the SNP markers on the linkage peak or in the "support zone" were included in several specific genes. The results showed that several SNP markers colocalized within these genes. Since we used a small SNP marker set, we considered that the 49 selected eQTs might not have been identified with the linkage analysis. 
Therefore, we searched the location of each selected eQT in the NCBI gene database to determine whether the location of each eQT coincided with the linkage peak.

Tables 3 and 4 show the relationship between genes pairs with LOD scores of $>2.0$. Eight genes, LRRIQ1, APOL3, APOL4, IGSF4, ASTN2, NRP1, SFXN1, and ASCL3, were located on the peak of eQTs, known as IGF1, UGCGL2, IDE, BCL2, BCAP29, VEGFB, PTPN6, and $A P O B E C 3 B$, respectively. Thirty-one genes were located in the support zone. Among the total 39 genes at both the peak point and support zone, 7 genes, known as APOL3, IGFBP2, BTG1, UGCGL2, LEPR, APOL6, and IRS2, were included in the 49 selected eQTs.

\section{Directed gene network construction}

The gene network was constructed with the selected eQTs, from which two groups of gene networks were formed, each around the genes IRS2 and UGCGL2 (Fig. 2). IRS2 was grouped with 6 genes, APOBEC3B, BTG1, HDLBP, IDE, IGF1, and IGFBP2. To explore the biological network, the functions of each gene were searched via the NCBI gene database. The IRS2 gene, which belongs to an insulin receptor substrate family, is known to play a role in the insulin signaling pathway. The cogrouped genes were also related to insulin metabolism. We found a stream from IGFBP2 to IDE, which consisted completely of genes that play a role in insulin

Table 2. LOD scores and linkage peak loci of the eQTs

\begin{tabular}{|c|c|c|c|c|}
\hline \multirow{2}{*}{$\frac{L O D}{>3}$} & \multicolumn{2}{|c|}{ eQTs (peak LOD score) } & \multirow[t]{2}{*}{ \# SNP marker } & \multirow{2}{*}{$\frac{\text { Linkage peak loci (cM) }}{\text { Chr5 }(69.94)}$} \\
\hline & ADFP & $(3.09)$ & & \\
\hline & IRS2 & $(3.08)$ & rs599825, rs1369330 & Chr2 (240.2) \\
\hline \multirow[t]{6}{*}{$>2.5$} & BCAP29 & $(2.68)$ & rs1326808, rs1372332 & Chr9 (126.13) \\
\hline & & & rs1334071, rs944985, rs871121 & Chr9 (126.38) \\
\hline & PTPN1 & $(2.70)$ & rs2007439, rs2051493, rs2040346 & Chr22 (19.44) \\
\hline & VLDLR & $(2.65)$ & rs1889383, rs1209485, rs1959068, rs1959064 & Chr14 (53.74) \\
\hline & & $(2.57)$ & rs1425244 & Chr11 (112.55) \\
\hline & VEGFB & $(2.63)$ & rs1360456, rs927099 & Chr10 (60.68) \\
\hline \multirow[t]{15}{*}{$>2$} & AРОВЕС3В & $(2.46)$ & rs1866661, rs2028383 & Chr2 (243.97) \\
\hline & BTG1 & $(2.07)$ & rs1425244 & Chr11 (112.55) \\
\hline & BCL2 & $(2.29)$ & rs1334071, rs944985, rs871121 & Chr9 (126.38) \\
\hline & IDE & $(2.50)$ & rs1013582, rs220860, rs220862 & Chr11 (122.22) \\
\hline & & $(2.37)$ & rs 1914735, rs 1914732 & Chr2 (118.65) \\
\hline & & $(2.17)$ & rs1341407, rs 778305 & Chr13 (107.14) \\
\hline & & $(2.02)$ & rs931283 & Chr5 (6.21) \\
\hline & & $(2.25)$ & rs1333820, rs1333798, rs1556569 & Chr13 (80.17) \\
\hline & IGF1 & $(2.07)$ & rs1507213, rs1032957 & Chr12 (84.03) \\
\hline & UGCGL2 & $(2.25)$ & rs1414277 & Chr1 (94.99) \\
\hline & & $(2.05)$ & rs739200, rs715550, rs878847, rs80576 & Chr22 (45.07) \\
\hline & UGP2 & $(2.44)$ & rs1851272, rs1521563, rs1402726, rs188914 & Chr17 (54.41) \\
\hline & & $(2.4)$ & rs1425244 & Chr11 (112.55) \\
\hline & & $(2.25)$ & rs1333820, rs1333798, rs1556569 & Chr13 (80.17) \\
\hline & PTPN6 & $(2.04)$ & rs265976, rs925197 & Chr5 (199.58) \\
\hline
\end{tabular}

Table 3. Genes located on the exact linkage peak loci of the eQTs

\begin{tabular}{llll}
\hline \multicolumn{1}{c}{ eQT } & \multicolumn{1}{c}{ Peak location $(\mathrm{Mbp} / \mathrm{cM})$} & \multicolumn{1}{c}{ \# SNP markers } & Gene located on peak \\
\hline APOBEC3B & Chr2 $(243.97 / 223.61)$ & rs1866661 & ASCL3 \\
BCAP29 & Chr9 $(126.13 / 116.61)$ & rs1372332 & ASTN2 \\
BCL2 & Chr9 $(126.38 / 116.89-117.07)$ & rs1334071, rs944985, rs220862 & ASTN2 \\
IDE & Chr11 $(122.22 / 114.74-114.80)$ & rs1013582, rs220860, rs220862 & IGSF4 \\
IGF1 & Chr12 $(99.65 / 84.02)$ & rs1507213, rs1032957 & LRRIQ1 \\
PTPN6 & Chr5 (199.58/174.87) & rs925197 & SFXN1 \\
UGCGL2 & Chr22 $(45.07 / 34.86)$ & rs80576 & APOL3 \\
& Chr22 $(45.07 / 34.90)$ & rs916336 & APOL4 \\
VEGFB & Chr10 (60.68/33.54-33.56) & rs1360456, rs927099 & NRP1
\end{tabular}

\footnotetext{
${ }^{a}$ Gene included in the selected 49 metabolic syndrome-related eQTs.
} 
Table 4. Genes located in the linkage support zone of the eQTs

\begin{tabular}{|c|c|c|c|c|}
\hline eQT & Peak location (Mbp/cM) & LOD & \# SNP markers & Support genes \\
\hline ADFP & Chr5 (69.94/54.26) & 2.71 & rs 33721, rs 27508 & MAST4 \\
\hline \multirow[t]{5}{*}{ IRS2 } & Chr2 (240.2/221.60-221.66) & 2.66 & rs1425118 & TMEM169 \\
\hline & & 2.72 & rs207908, rs207928 & XRCC5 \\
\hline & & 2.72 & rs207823, rs83612 & $\begin{array}{l}\text { MARCH_4 } \\
\text { IGFBP2 }^{\mathrm{a}}\end{array}$ \\
\hline & & 2.69 & rs1866661 & ASCL3 \\
\hline & & 2.63 & rs1431079, rs1431077, rs1431087 & KIAA1486 \\
\hline \multirow[t]{7}{*}{ APOBEC3B } & Chr2 (243.97/223.61) & 2.4 & rs1431079, rs1431077, rs1431087 & KIAA1486 \\
\hline & & 2.35 & rs933602 & DNER \\
\hline & & 2.26 & rs2053921, rs1669086 & ARMC9 \\
\hline & & 2.05 & rs1284 & GIGYF2 \\
\hline & & 2.05 & rs938569 & NGEF \\
\hline & & & & IGFBP2 $^{\mathrm{a}}$ \\
\hline & & & & HDLBP $^{a}$ \\
\hline \multirow[t]{2}{*}{ VLDLR } & Chr11 (112.55-106.54) & 2.3 & rs1013582 & IGSF4 \\
\hline & & 2.22 & rs721487 & DSCAML1 \\
\hline \multirow[t]{2}{*}{ IDE } & Chr11 (122.22/114.74-114.80) & 2.16 & rs721487 & DSCAML1 \\
\hline & Chr13 $(105.71 / 109.07)$ & 2.08 & rs2039120, rs354439 & $\mathrm{IRS} 2^{\mathrm{a}}$ \\
\hline \multirow[t]{3}{*}{ UGP2 } & Chr13 (81.17/87.53-87.56) & 1.93 & rs2031540 & CLDN10 \\
\hline & & 1.96 & rs639527 & HS6ST3 \\
\hline & & & & UGCGL2 ${ }^{\mathrm{a}}$ \\
\hline \multirow[t]{8}{*}{ UGCGL2 } & Chr1 (94.99/61.12) & 1.83 & rs991191, rs1465564, rs976574 & INADL \\
\hline & & 1.89 & rs2172962 & IL12RB2 \\
\hline & & 1.85 & rs1511687 & GNG12 \\
\hline & & & & LEPR $^{a}$ \\
\hline & Chr22 $(45.07 / 34.86,34.90)$ & 1.89 & rs1476576 & OSM \\
\hline & & 1.89 & rs1076297 & CCDC157 \\
\hline & & 1.9 & rs2157199, rs2032474, rs933214 & LARGE \\
\hline & & & & APOL6 $^{\mathrm{a}}$ \\
\hline \multirow[t]{3}{*}{ IGF1 } & Chr12 (99.65/84.02) & 1.77 & rs1882535, rs2141876 & PPFIA2 \\
\hline & & 1.87 & rs1520723 & CCDC41 \\
\hline & & & & $\mathrm{BTG}^{\mathrm{a}}$ \\
\hline \multirow[t]{2}{*}{ BTG1 } & Chr11 (112.5/106.54) & 1.79 & rs1318933 & RDX \\
\hline & & 1.87 & rs1013582, rs220860, rs220862 & IGSF4 \\
\hline
\end{tabular}

${ }^{a}$ Gene included in the selected 49 metabolic syndrome-related eQTs.

metabolism. The UGCGL2 gene is known to transfer glycosyl groups (Arnold and Kaufman, 2003). It showed a directed network with 4 genes, known as APOL3, APOL6, LEPR, and UGP2. This grouped network showed a pathway of adipose, lipid, and glucose metabolites. LEPR, the leptin receptor, is known to be related to adipose tissue mass regulation (Kershaw and Flier, 2004; Ronti et al., 2006). APOL3 and APOL6 both play a role in lipid metabolism, in lipid transportation and lipid binding, respectively. UGP2, which was identified as being influenced by UGCGL2 in our study, undertakes glucose transfer, especially in liver and muscle tissues. The shape of the gene network between the two groups is distinct. The network around the IRS2 gene displays a flow of the insulin pathway. However, in the second group surrounding the UGCGL2 gene, 3 of the other genes that were identified influence UGCGL2. According to these results, we can propose that IRS2 plays a role as an intermediator in the insulin metabolism pathway and that UGCGL2 appears to be at the center of the lipid and glucose metabolism pathway.

\section{Discussion}

In this study, we aimed to construct a directed gene network that was related to metabolic syndrome via comparison of the linkage peak loci and LOD scores of selected eQTs. Since the genetics of metabolic syndrome is polygenic and heterogeneous (Mercado et al., 2002), the gene set approach that we have presented in this study can be helpful in understanding the genetic components of the disease. We explored the direction that supported the biological gene function. Two groups of gene networks were constructed, each surrounding the 

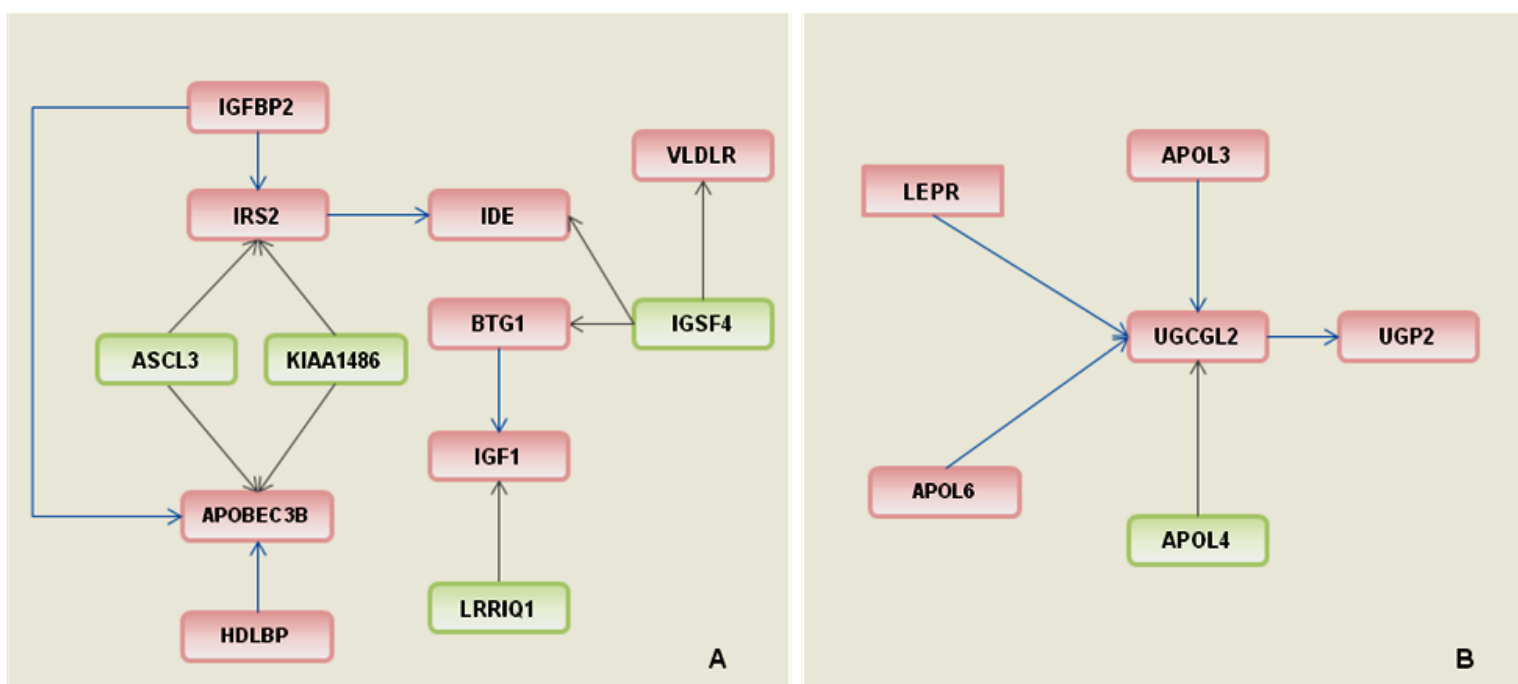

Fig. 2. Constructed gene network around IRS2 and UGCGL2. Genes pertaining to the selected 49eQTs are presented in the pink box. Other genes, identified with the SNP marker located in the support zone, are shown in the green box. The arrow pointing from the former to the latter gene indicates the causal direction. (A) Gene network around IRS2 with 12 genes. (B) Gene network around UGCGL2 with 5 genes.

genes IRS2 and UGCGL2. The former networking group showed the pathway that was related to insulin metabolism, and the latter represented lipid and glucose metabolism.

We identified the direction among gene-gene interactions, and several genes could be supported with known biological pathways, reported in previous studies. For example, the BTG1 gene was identified in our study as belonging to a group that was surrounded with IRS2, which belongs to a family of insulin receptor substrate proteins (Saltiel and Kahn, 2001). It supports the known biological correlation that gene expression of BTG1 is regulated by insulin (Kuiperij, 2004). Insulin also plays a role in the insulin-like growth factor-binding protein (IGFBP) system (Kelley et al., 1996), as shown in the relationship between IRS2 and IGFBP2 in the present study. Also, we could find the IGF1 and IRS2 genes in the same network in this study, which could be supported by a previous report that demonstrated that a decrease in IGF1 causes the degradation of IRS2 (Rui et al., 2001). We also found studies that support our results regarding the second group (e.g., leptin is associated with glucose levels) (Schwartz et al., 1996).

According to our results, the leptin receptor LEPR gene affects a glucose-related gene, UGCGL2. Apolipoprotein-related genes, such as APOL3, APOL4, and APOL6, in our gene network are also associated with glucose metabolism, as suggested by increased apolipoprotein levels in glucose-impaired patients (Pietzsch et al., 1998).

Since the biological correlation between endocrine- metabolic components remains undiscovered, we could not confirm the relationship between all of the genes in our network. However, our results also support the evidence of a gene network, which was not based solely on biological evidence. We intended to replicate our results with a prior gene network model, which included gene function with the network construction (Franke et al., 2006). A gene pathway previously known via Franke et al. was found in our study to have relatively simple structure associated with a higher LOD score. The network between the genes ASCL and APOBEC3B $(\mathrm{LOD}=2.46)$ consists of only 3 genes. In contrast, BTG1 and IGF1 (LOD=1.5) constitute a more complex network with 12 related genes (Fig. 3). We can suppose that higher LOD scores indicate a stronger effect on other genes and that their biological pathway is more directly associated with each other.

This study presents a robust, directed causal network construction via linkage analysis. Linkage analysis and eQTs can be utilized to explore gene-gene interaction mechanisms, including their biological implications. We also anticipate that our method will help overcome the challenge of computational complexity and the cost of constructing genetic networks (Markou and Singh, 2003b; Wessels et al., 2001) due to the simplicity of linkage analysis to identify gene expression loci.

However, this method of genetic network construction has several limitations. A linkage analysis with additional SNP markers, which will increase its density, may generate more accurate LOD scores and increase the linkage support zone. An analysis with more eQTs and oth- 


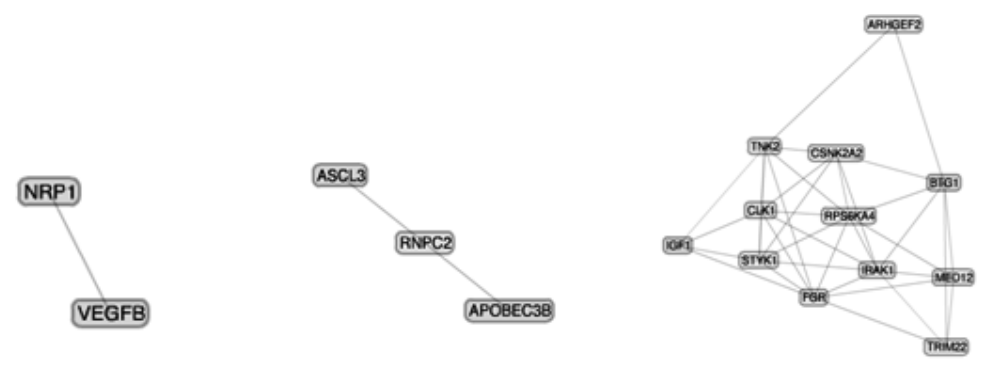

Fig. 3. Evidence of gene-gene

A. Direct network between NRP1 B. Simple network between ASCL3 and VEGFB $(\mathrm{LOD}=2.63)$
C. Complex network between BTGl and IGFl (LOD=1.8) interactions from the network database (Franke et al., 2006). er criteria to establish boundaries of the "support zone" can also affect the results. However, in our study, the support zone had LOD scores $>1.7$. We considered this boundary to be acceptable, based on an LOD score range of 1.7-1.8, which has been considered potential evidence of linkage among genes (Avery et al., 2004; Comuzzie et al., 2001; Lindgren et al., 2002; Zhu et al., 2002).

Despite these limitations, we anticipate that our study will contribute to the understanding of the genetic components that are involved in metabolic syndrome. Our methodology supports the characterization and location of eQTs as an effective approach for constructing a genetic network.

\section{Acknowledgements}

This study was supported by the BK21 program.

\section{References}

Arnold, S.M. and Kaufman, R.J. (2003). The noncatalytic portion of human UDP-glucose, glycoprotein glucosyltransferase 1 confers UDP-glucose binding and transferase function to the catalytic domain. J. Biol. Chem. 278, 43320-43328.

Avery, C.L., Freedman, B.I., Heiss, G., Kraja, A., Rice, T., Arnett, D., Miller, M.B., Pankow, J.S., Lewis, C.E., Myers, R.H., Hunt, S.C., Almasy, L., North, K.E., and Hypertension Genetic Epidemiology Network. (2004). Linkage analysis of diabetes status among hypertensive families, the Hypertension Genetic Epidemiology Network study. Diabetes 53 , 3307-3312.

Bonnet, F., Patel, S., Laville, M., Balkau, B., Favuzzi, A., Monti, L.D., Lalic, N., and Walker, M. (2008). Influence of the ACE gene insertion/deletion polymorphism on insulin sensitivity and impaired glucose tolerance in healthy subjects. Diabetes Care 31, 789-794.

Bouzakri, K., Zachrisson, A., Al-Khalili, L., Zhang, B.B., Koistinen, H.A., Krook, A., and Zierath, J.R. (2006). siRNAbased gene silencing reveals specialized roles of IRS-1/ Akt2 and IRS-2/Akt1 in glucose and lipid metabolism in human skeletal muscle. Cell Metab. 4, 89-96.
Cheung, V.G. and Spielman, R.S. (2007). Data for Genetic Analysis Workshop (GAW) 15, Problem 1, genetics of gene expression variation in humans. BMC Proc. 1 Suppl $1, \mathrm{~S} 2$.

Comuzzie, A.G., Funahashi, T., Sonnenberg, G., Martin, L.J., Jacob, H.J., Black, A.E., Maas, D., Takahashi, M., Kihara, S., Tanaka, S., Matsuzawa, Y., Blangero, J., Cohen, D., and Kissebah, A. (2001). The genetic basis of plasma variation in adiponectin, a global endophenotype for obesity and the metabolic syndrome. J. Clin. Endocrinol. Metab. 86, 4321-4325.

de Jong, $H$. (2002). Modeling and simulation of genetic regulatory systems, a literature review. J. Comput. Biol. 9, 67-103.

Foufelle, F. and Ferre, P. (2002). New perspectives in the regulation of hepatic glycolytic and lipogenic genes by insulin and glucose, a role for the transcription factor sterol regulatory element binding protein-1c. Biochem. J. 366, 377-391.

Franke, L., van Bakel, $H_{\text {., }}$ Fokkens, L., de Jong, E.D., Egmont-Petersen, M., and Wijmenga, C. (2006). Reconstruction of a functional human gene network, with an application for prioritizing positional candidate genes. $\mathrm{Am}$. J. Hum. Genet. 78, 1011-1025.

Groop, L. (2000). Genetics of the metabolic syndrome. Br. J. Nutr. 83 Suppl 1, S39-48.

Hasty, J., McMillen, D., Isaacs, F., and Collins, J.J. (2001). Computational studies of gene regulatory networks, in numero molecular biology. Nat. Rev. Genet. 2, 268-279.

Horenstein, R.B. and Shuldiner, A.R. (2004). Genetics of diabetes. Rev. Endocr. Metab. Disord. 5, 25-36.

Kantartzis, K., Peter, A., Machicao, F., Machann, J., Wagner, S., Konigsrainer, I., Konigsrainer, A., Schick, F., Fritsche, A., Haring, H.U., and Stefan, N. (2009). Dissociation between Fatty Liver and Insulin Resistance in Humans carrying a Variant of the Patatin-like Phospholipase 3 Gene. Diabetes. 58, 2616-2623.

Kelley, K.M., Oh, Y., Gargosky, S.E., Gucev, Z., Matsumoto, T., Hwa, V., Ng, L., Simpson, D.M., and Rosenfeld, R.G. (1996). Insulin-like growth factor-binding proteins (IGFBPs) and their regulatory dynamics. Int. J. Biochem. Cell Biol. 28, 619-637.

Kershaw, E.E and Flier, J.S, (2004). Adipose Tissue as an Endocrine Organ. J. Clin. Endocrinol. Metab. 89, 25482556. 
Kopf, D., Cheng, L.S., Blandau, P., Hsueh, W., Raffel, L.J., Buchanan, T.A., Xiang, A.H., Davis, R.C., Rotter, J.I., and Lehnert, $H$. (2008). Association of insulin sensitivity and glucose tolerance with the $c .825 \mathrm{C}>\mathrm{T}$ variant of the $\mathrm{G}$ protein beta-3 subunit gene. J. Diabetes Complicat. 22, 205-209.

Kuiperij, H. (2004). Chapter 4; Expression profiling of cAMPregulated genes via MAPK-dependent and -independent pathways. Novel cAMP Targets in Cell Proliferation pp. 53-80.

Kulp, D.C. and Jagalur, M. (2006). Causal inference of regulator-target pairs by gene mapping of expression phenotypes. BMC Genomics 7, 125.

Lindgren, C.M., Mahtani, M.M., Widen, E., McCarthy, M.I., Daly, M.J., Kirby, A., Reeve, M.P., Kruglyak, L., Parker, A., Meyer, J. Almgren, P., Lehto, M., Kanninen, T., Tuomi, T., Groop, L.C., and Lander, E.S. (2002). Genomewide search for type 2 diabetes mellitus susceptibility loci in Finnish families, the Botnia study. Am. J. Hum. Genet. 70, 509-516.

Ma, L., Hanson, R.L., Que, L.N., Cali, A.M., Fu, M., Mack, J.L., Infante, A.M., Kobes, S., Bogardus, C., Shuldiner, A.R. and Baier, L.J. (2007). Variants in ARHGEF11, a candidate gene for the linkage to type 2 diabetes on chromosome 1q, are nominally associated with insulin resistance and type 2 diabetes in Pima Indians. Diabetes 56, 1454-1459.

Markou, M. and Singh, S. (2003a). Novelty detection, a review-part 1, statistical approaches. Singnal Processing 83, 2481-2497.

Markou, M. and Singh, S. (2003b). Novelty detection, a review-part 2, neural network based approaches. Singnal Processing 83, 23.

Matise, T.C., Chen, F., Chen, W., De La Vega, F.M., Hansen, M., He, C., Hyland, F.C., Kennedy, G.C., Kong, X., Murray, S.S. Ziegle, J.S., Stewart, W.C., and Buyske, S. (2007). A second-generation combined linkage physical map of the human genome. Genome Res. 17, 17831786.

Mercado, M.M., McLenithan, J.C., Silver, K.D., and Shuldiner, A.R. (2002). Genetics of insulin resistance. Curr. Diab. Rep. 2, 83-95.

Morley, M., Molony, C.M., Weber, T.M., Devlin, J.L., Ewens, K.G., Spielman, R.S., and Cheung, V.G. (2004). Genetic analysis of genome-wide variation in human gene expression. Nature 430, 743-747.

Mussig, K., Staiger, H., Machicao, F., Kirchhoff, K., Guthoff, M., Schafer, S.A., Kantartzis, K., Silbernagel, G., Stefan, N., Holst, J.J. Gallwitz, B., Häring, H.U., and Fritsche, A. (2009). Association of type 2 diabetes candidate polymorphisms in KCNQ1 with incretin and insulin secretion. Diabetes 58, 1715-1720

Pietzsch, J., Julius, U., Nitzsche, S., and Hanefeld, M. (1998). In vivo evidence for increased apolipoprotein A-I catabolism in subjects with impaired glucose tolerance. Diabetes 47, 1928-1934.

Previs, S.F., Withers, D.J., Ren, J.M., White, M.F., and Shulman, G.I. (2000). Contrasting effects of IRS-1 versus IRS-2 gene disruption on carbohydrate and lipid metabo- lism in vivo. J. Biol. Chem. 275, 38990-38994.

Reaven, G. (2002). Metabolic syndrome, pathophysiology and implications for management of cardiovascular disease. Circulation 106, 286-288.

Reaven, G.M. (1988). Banting lecture 1988. Role of insulin resistance in human disease. Diabetes 37, 1595-1607.

Rockman, M.V. and Kruglyak, L. (2006). Genetics of global gene expression. Nat. Rev. Genet. 7, 862-872.

Ronti, T, Lupattelli, G, and Mannarino, E. (2006). The endocrine function of adipose tissue, an update. Clin. Endocrinol. 64, 4, 355-365.

Rui, L., Fisher, T.L., Thomas, J., and White, M.F. (2001). Regulation of insulin/insulin-like growth factor-1 signaling by proteasome-mediated degradation of insulin receptor substrate-2. J. Biol. Chem. 276, 40362-40367.

Sale, M.M., Woods, J., and Freedman, B.I. (2006). Genetic determinants of the metabolic syndrome. Curr. Hypertens. Rep. 8, 16-22.

Saltiel, A.R. and Kahn, C.R. (2001). Insulin signalling and the regulation of glucose and lipid metabolism. Nature 414, 799-806.

Schadt, E.E., Lamb, J., Yang, X., Zhu, J., Edwards, S., Guhathakurta, D., Sieberts, S.K., Monks, S., Reitman, M., Zhang, C., Lum, P.Y., Leonardson, A., Thieringer, R., Metzger, J.M., Yang, L., Castle, J., Zhu, H., Kash, S.F., Drake, T.A., Sachs, A., and Lusis, A.J. (2005). An integrative genomics approach to infer causal associations between gene expression and disease. Nat. Genet. 37, 710-717.

Schadt, E.E. and Lum, P.Y. (2006). Thematic review series, systems biology approaches to metabolic and cardiovascular disorders. Reverse engineering gene networks to identify key drivers of complex disease phenotypes. $J$. Lipid Res. 47, 2601-2613.

Schulingkamp, R.J., Pagano, T.C., Hung, D., and Raffa, R.B. (2000). Insulin receptors and insulin action in the brain, review and clinical implications. Neurosci. Biobehav. Rev. 24, 855-872.

Schwartz, M.W., Baskin, D.G., Bukowski, T.R., Kuijper, J.L., Foster, D., Lasser, G., Prunkard, D.E., Porte, D., Jr., Woods, S.C., Seeley, R.J. and Weigle, D.S. (1996). Specificity of leptin action on elevated blood glucose levels and hypothalamic neuropeptide $\mathrm{Y}$ gene expression in ob/ob mice. Diabetes 45, 531-535.

Stern, M.P. (2003). Genetics of insulin resistance syndrome. Endocr. Pract. 9 Suppl 2, 35-38.

Tu, Z., Wang, L., Arbeitman, M.N., Chen, T., and Sun, F. (2006). An integrative approach for causal gene identification and gene regulatory pathway inference. Bioinformatics 22, e489-496.

Vasseur, F., Meyre, D., and Froguel, P. (2006). Adiponectin, type 2 diabetes and the metabolic syndrome, lessons from human genetic studies. Expert. Rev. Mol. Med. 8, 1-12.

Vohradsky, J. (2001). Neural model of the genetic network. J. Biol. Chem, 276, 36168-36173.

Wang, H., Zhang, H., Jia, Y., Zhang, Z., Craig, R., Wang, $X$., and Elbein, S.C. (2004). Adiponectin receptor 1 gene (ADIPOR1) as a candidate for type 2 diabetes and insulin 
resistance. Diabetes 53, 2132-2136.

Wessels, L.F., van Someren, E.P., and Reinders, M.J. (2001). A comparison of genetic network models. Pac. Symp. Biocomput. 508-519.

Yang, W.S. and Chuang, L.M. (2006). Human genetics of adiponectin in the metabolic syndrome. J. Mol. Med. 84, 112-121.

Yu, K., Li, Q., Bergen, A.W., Pfeiffer, R.M., Rosenberg, P.S.,
Caporaso, N., Kraft, P., and Chatterjee, N. (2009). Pathway analysis by adaptive combination of p-values. Genet. Epidemiol. 38, 700-709.

Zhu, X., Cooper, R.S., Luke, A., Chen, G., Wu, X., Kan, D., Chakravarti, A., and Weder, A. (2002). A genome-wide scan for obesity in African-Americans. Diabetes 51, 541544. 